\title{
Supporting Information \\ Mechanism of the Palladium-Catalyzed Homocoupling of Aryl-Boronic Acids: Key Involvement of a Palladium Peroxo Complex
}

\author{
Carlo Adamo, ${ }^{\text {a }}$ Christian Amatore, ${ }^{* \mathrm{~b}}$ Ilaria Ciofini, ${ }^{\mathrm{a}}$ Anny Jutand, ${ }^{* \mathrm{~b}}$ Hakim Lakmini ${ }^{\mathrm{b}}$ \\ ${ }^{a}$ Ecole Nationale Supérieure de Chimie, Laboratoire d'Electrochimie et Chimie Analytique, \\ UMR CNRS 7575, 11 Rue Pierre et Marie Curie. F-75231 Paris Cedex 5, France \\ ${ }^{b}$ Ecole Normale Supérieure, Département de Chimie, UMR CNRS-ENS-UPMC 8640 \\ 24 Rue Lhomond. F-75231 Paris Cedex 5, France
}

\section{General kinetic laws.}

An experimental reaction-order of +1 and +2 has been found for $\mathbf{4}$ and $\mathbf{1}$ respectively (in excess of $\mathbf{1}$ ). The following mechanism has been examined to ascertain the experimental results.

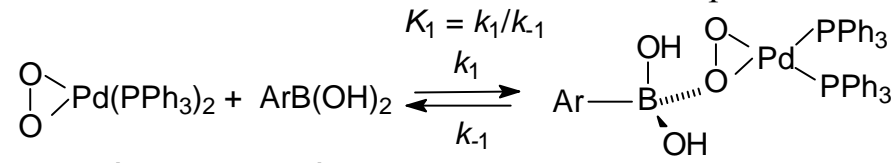

4

1

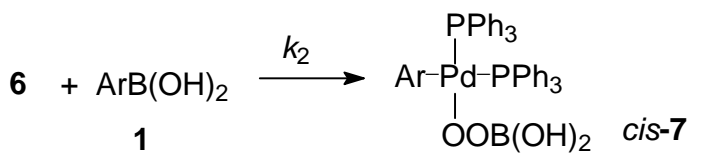

6

The experimental rate for the peroxo complex 4 consumption is expressed by the following equation with $\alpha=1$ and $\beta=2$ : rate $=k[4]^{\alpha}[1]^{\beta}$. An analytical expression of the rate can be obtained by solving the following coupled differential equations:

$$
\begin{aligned}
& \frac{\mathrm{d}[\mathbf{4}]}{\mathrm{dt}}=-k_{1}[\mathbf{4}][\mathbf{1}]+k_{-1}[\mathbf{6}] \\
& \frac{\mathrm{d}[\mathbf{6}]}{\mathrm{dt}}=k_{1}[\mathbf{4}][\mathbf{1}]-\left(k_{-1}+k_{2}[\mathbf{1}]\right)[\mathbf{6}] \\
& \frac{\mathrm{d}[c i s-7]}{\mathrm{dt}}=k_{2}[\mathbf{6}][\mathbf{1}]
\end{aligned}
$$

This general case (excess of $\mathbf{1}$ ) will be noted na (no approximation). However, some approximations could be made to simplify the kinetic problem and to derive analytical solutions of the rate law.

If the reaction rate of complex 6 in reaction (2) is sufficiently slow so that the first reaction may be considered as being at equilibrium, the relation between rates becomes: $k_{-1}[\mathbf{6}]>>k_{2}$ [6][1]. This approximation corresponds to the pre-equilibrium approximation (noted pe). The second step (Eq 2) is thus the rate determining step. The rate of peroxo complex consumption then becomes:

$$
\mathrm{v}=\frac{k_{1} k_{2}}{k_{-1}}[\mathbf{4}][\mathbf{1}]^{2}
$$

In the opposite case, where $k_{-1}[\mathbf{6}]<<k_{2}[\mathbf{6}][\mathbf{1}]$, the concentration of $\mathbf{6}$ is small, and remains constant. This approximation corresponds to the steady state hypothesis (noted ss). The forward reaction in Eq (1) is thus the rate determining step. The rate of peroxo complex consumption becomes: $v=k_{1}[4][1]$. However, these three cases may a priori be in competition. Competition parameters, $\mathrm{p}_{\mathrm{i}}$, may be introduced, such as the ratio of the average concentration of the key species obtained when each case is considered alone. ${ }^{29}$

$$
\mathrm{p}_{1}=\frac{[6]^{\mathrm{ss}}}{[6]^{\mathrm{pe}}}, \quad \mathrm{p}_{2}=\frac{[6]^{\mathrm{na}}}{[6]^{\mathrm{pe}}}, \mathrm{p}_{3}=\frac{[6]^{\mathrm{ss}}}{[6]^{\mathrm{na}}}=\frac{\mathrm{p}_{1}}{\mathrm{p}_{2}}
$$

The average concentration may be expressed as:

$$
[6]^{\mathrm{ss}}=\frac{k_{1} \mathrm{C}^{\circ}}{k_{2}},[6]^{\mathrm{pe}}=\frac{k_{1} \mathrm{C}^{\circ}[\mathbf{1}]}{k_{-1}},[6]^{\mathrm{na}}=\mathrm{C}^{\circ}
$$

where $C^{\circ}$ is the limit concentration of 4 . Thus, one has: 


$$
\mathrm{p}_{1}=\frac{k_{-1}}{k_{2}[\mathbf{1}]}, \mathrm{p}_{2}=\frac{k_{-1}}{k_{1}[\mathbf{1}]}, \mathrm{p}_{3}=\frac{k_{1}}{k_{2}}
$$

When a species is formed at a given rate, the faster its consumption, the smaller its concentration is. Consequently, if many mechanisms are in competition, the major mechanism is that leading to the smallest concentration of the key intermediate species. Figure S1 shows the kinetic zone diagram representing the competition between the three mechanisms and their interconnections.

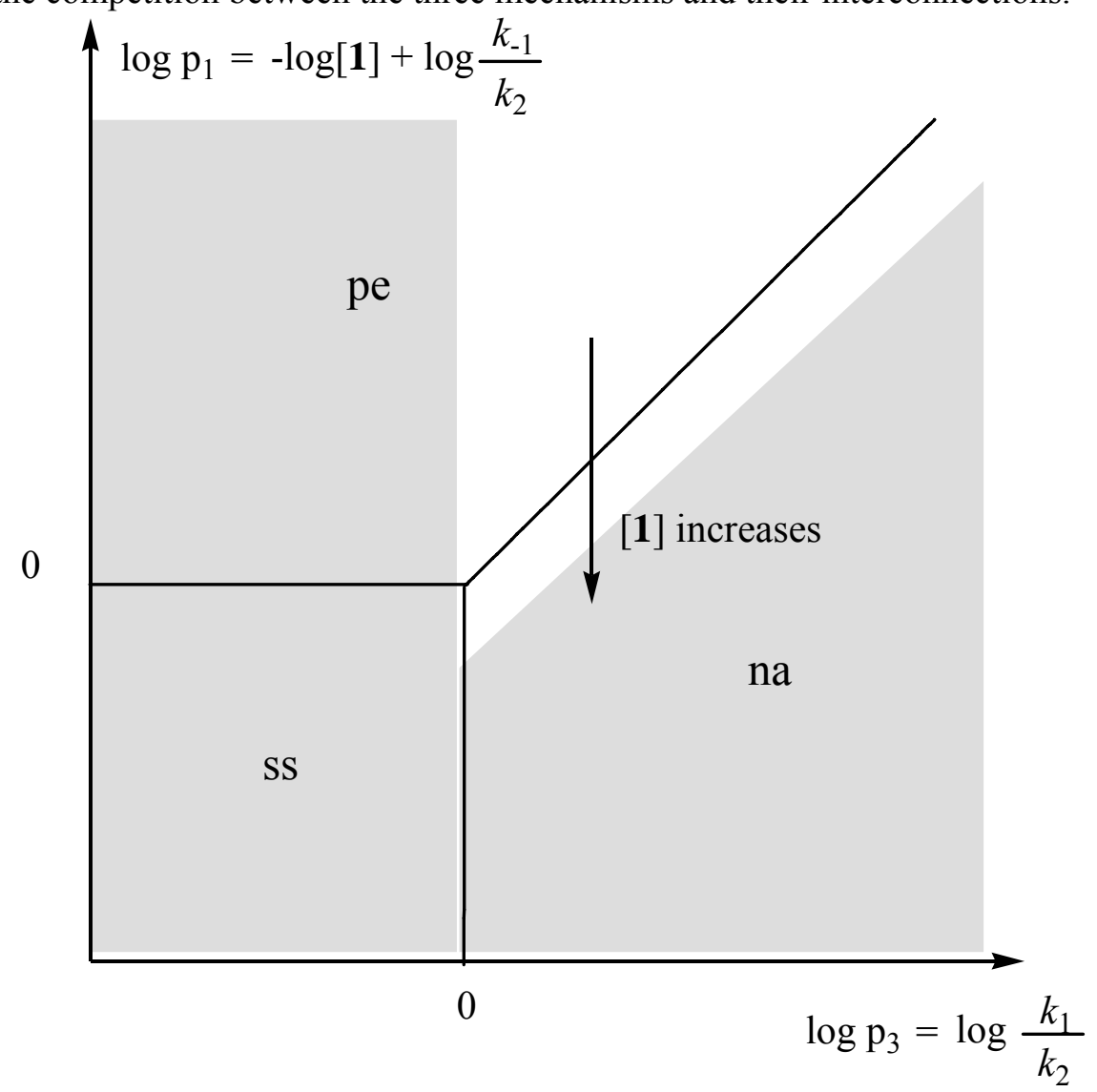

Figure S1. Kinetic zone diagram for the competition between three cases, na, pe and ss. The shaded area is not available for our system.

According to this diagram, the experimental results obtained in this work suggest that the mechanism depicted above and in Scheme 9, is close to the boundary between the pre-equilibrium domain (pe) and the domain where no approximation is done (na). This explains why the system may be shifted more or less towards each limiting case when [1] is varied (note that since $k_{1}>>k_{2}$, then $\log _{3}>>0$ ).

For substoichiometric concentrations of $\mathbf{1}$ (see ${ }^{31} \mathrm{P}$ NMR investigations), the system cannot proceed all the way to the formation of cis-7 and stops at the level of $\mathbf{6}$ (less than 1 equiv of $\mathbf{1}$ ) or to that of a mixture of $\mathbf{6}$ and cis-7. ${ }^{25}$

\section{References}

(12) Frisch, M. J.; Trucks, G. W.; Schlegel, H. B.; Scuseria, G. E.; Robb, M.A.; Cheeseman, J. R.; Zakrzewski, V. G.; Montgomery, J. A., Jr.; Stratmann, R. E.; Burant, J. C.; Dapprich, S.; Millam, J. M.; Daniels, A. D.; Kudin, K. N.; Strain, M. C.; Farkas, O.; Tomasi, J.; Barone, V.; Cossi, M.; Cammi, R.; Mennucci, B.; Pomelli, C.; Adamo, C.; Clifford, S.; Ochterski, J.; Petersson, G. A.; Ayala, P. Y.; Cui, Q.; Morokuma, K.; Malick, D. K.; Rabuck, A. D.; Raghavachari, K.; Foresman, J. B.; Cioslowski, J.; Ortiz, J. V.; Baboul, A. G.; Stefanov, B. B.; Liu, G.; Liashenko, A.; Piskorz, P.; Komaromi, I.; Gomperts, R.; Martin, R. L.; Fox, D. J.; Keith, T.; Al-Laham, M. A.; Peng, C. Y.; Nanayakkara, A.; Gonzalez, C.; Challacombe, M.;Gill, P. M. W.; Johnson, B.; Chen, W.; Wong, M. W.; Andres, J. L.; Gonzalez, C.; Head-Gordon, M.; Replogle; E. S.; Pople, J. A. Gaussian 03, Revision B5; Gaussian, Inc.: Pittsburgh, PA, 2003. 
(30) Amatore C. Relations between Micro- and Macrophenomena. In Organic Electrochemistry. Dekker, M. Inc; New York, Basel, Hong Kong. Eds Lund, H.; Baizer, M. M. 1991, pp. 207-232.

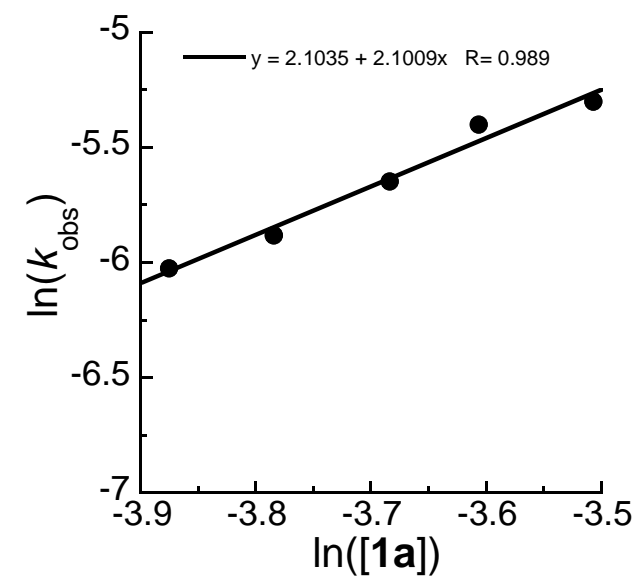

Figure S2. Kinetics of the reaction of the arylboronic acid 1a with $\left(\eta^{2}-\mathrm{O}_{2}\right) \mathrm{Pd}\left(\mathrm{PPh}_{3}\right)_{2} 4\left(C_{0}=2 \mathrm{mM}\right)$ in DMF (containing $\left.n \mathrm{Bu}_{4} \mathrm{NBF}_{4}, 0.3 \mathrm{M}\right)$ at $25^{\circ} \mathrm{C}$, as monitored by amperometry at a rotating gold disk electrode $\left(d .2 \mathrm{~mm}, \omega=105\right.$ rad. $\left.\mathrm{s}^{-1}\right)$ polarized at $+0.70 \mathrm{~V}$ on the plateau of the oxidation wave of 4. Determination of the reaction order in 1a: plot of $\ln \left(k_{\mathrm{obs}}\right)$ against $\ln ([\mathbf{1} \mathbf{a}]): \ln \left(k_{\mathrm{obs}}\right)=2.1 \times \ln ([\mathbf{1} \mathbf{a}])$

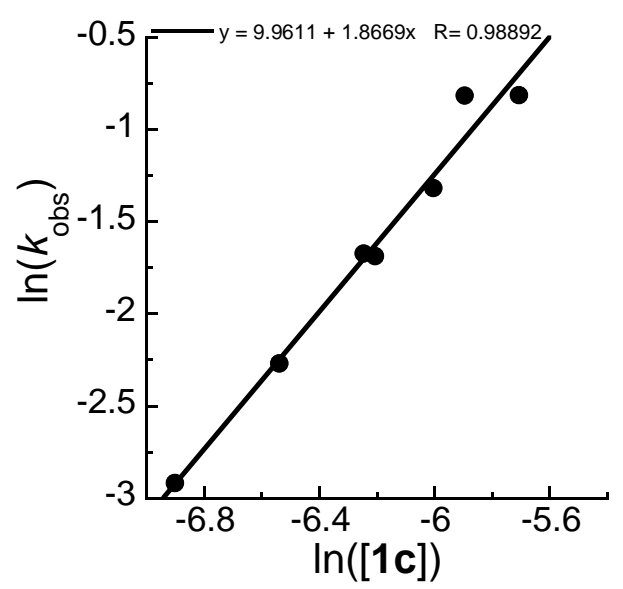

Figure S3. Kinetics of the reaction of the arylboronic acid 1c with $\left(\eta^{2}-\mathrm{O}_{2}\right) \mathrm{Pd}\left(\mathrm{PPh}_{3}\right)_{2} \quad 4 \quad\left(C_{0}=2 \mathrm{mM}\right)$ in $\mathrm{DMF}$ (containing $n \mathrm{Bu}_{4} \mathrm{NBF}_{4}, 0.3 \mathrm{M}$ ) at $25{ }^{\circ} \mathrm{C}$, as monitored by amperometry at a rotating gold disk electrode $(d .2 \mathrm{~mm}, \omega=$ $105 \mathrm{rad} . \mathrm{s}^{-1}$ ) polarized at $+0.70 \mathrm{~V}$ on the plateau of the oxidation wave of 4 . Determination of the reaction order in 1c: plot of $\ln \left(k_{\text {obs }}\right)$ against $\ln ([\mathbf{1 c}]): \ln \left(k_{\text {obs }}\right)=1.86 \times \ln ([\mathbf{1 c}])$ 


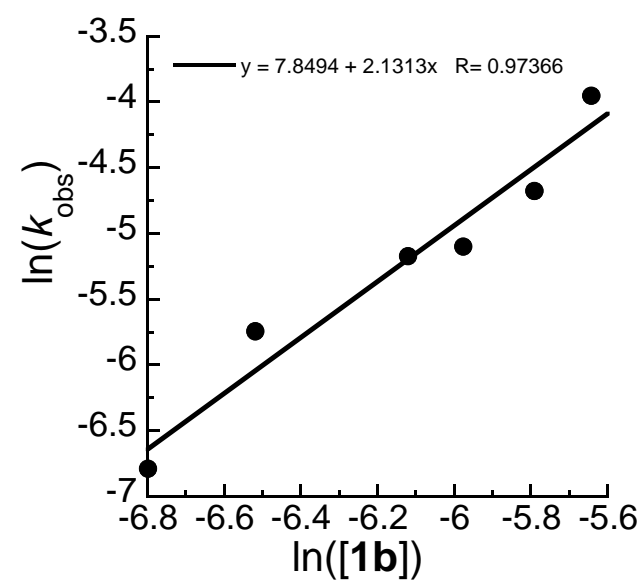

Figure S4. Kinetics of the reaction of the arylboronic acid 1 b with $\left(\eta^{2}-\mathrm{O}_{2}\right) \mathrm{Pd}\left(\mathrm{PPh}_{3}\right)_{2} 4\left(C_{0}=2 \mathrm{mM}\right)$ in DMF (containing $n \mathrm{Bu}_{4} \mathrm{NBF}_{4}, 0.3 \mathrm{M}$ ) at $25{ }^{\circ} \mathrm{C}$, as monitored by amperometry at a rotating gold disk electrode $(d .2 \mathrm{~mm}, \omega=$ $105 \mathrm{rad}_{\mathrm{s}}^{-1}$ ) polarized at $+0.70 \mathrm{~V}$ on the plateau of the oxidation wave of 4 . Determination of the reaction order in 1b: plot of $\ln \left(k_{\text {obs }}\right)$ against $\ln ([\mathbf{1 b}]): \ln \left(k_{\text {obs }}\right)=2.13 \times \ln ([\mathbf{1 b}])$

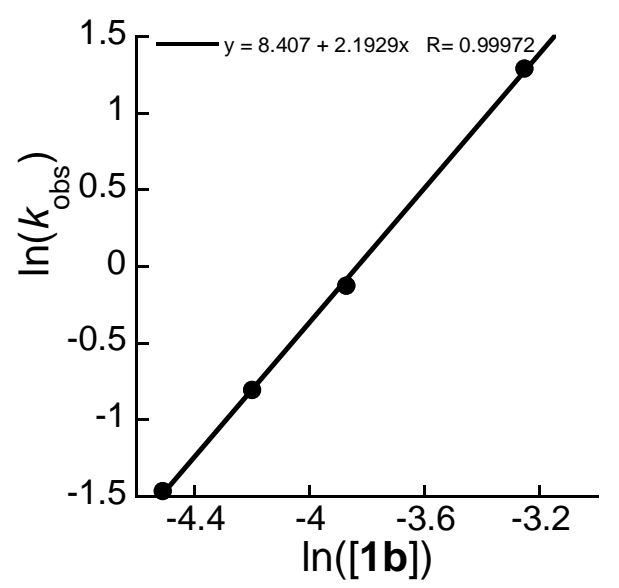

Figure S5. Kinetics of the reaction of the arylboronic acid $1 b$ with $\left(\eta^{2}-\mathrm{O}_{2}\right) \mathrm{Pd}\left(\mathrm{PPh}_{3}\right)_{2} 4\left(C_{0}=2 \mathrm{mM}\right)$ in chloroform (containing $n \mathrm{Bu}_{4} \mathrm{NBF}_{4}, 0.3 \mathrm{M}$ ) at $25{ }^{\circ} \mathrm{C}$, as monitored by amperometry at a rotating gold disk electrode $(d .2 \mathrm{~mm}, \omega=$ 105 rad. $\mathrm{s}^{-1}$ ) polarized at $+0.70 \mathrm{~V}$ on the plateau of the oxidation wave of 4 . Determination of the reaction order in 1b: plot of $\ln \left(k_{\text {obs }}\right)$ against $\ln ([\mathbf{1 b}]): \ln \left(k_{\text {obs }}\right)=2.19 \times \ln ([\mathbf{1 b}])$ 
Table S1. Optimized structure of the peroxo complex $\left(\eta^{2}-\mathrm{O}_{2}\right) \mathrm{Pd}\left(\mathrm{PPh}_{3}\right)_{2}$ (the labelling is reported in Figure 1). Distances $d$ in $\AA$ and angles $\theta$ in degrees

\begin{tabular}{cccc}
\hline & LANL2DZ & BS2 & X-ray $^{\mathrm{a}}$ \\
\hline$d\left(\mathrm{O}_{\mathrm{a}}-\mathrm{O}_{\mathrm{b}}\right)$ & 1.429 & 1.350 & 1.421 \\
$d\left(\mathrm{Pd}-\mathrm{O}_{\mathrm{a}}\right)$ & 2.043 & 2.039 & 1.999 \\
$d\left(\mathrm{Pd}-\mathrm{O}_{\mathrm{b}}\right)$ & 2.061 & 2.052 & 2.013 \\
$d\left(\mathrm{Pd}-\mathrm{P}_{\mathrm{a}}\right)$ & 2.400 & 2.337 & 2.272 \\
$d\left(\mathrm{Pd}-\mathrm{P}_{\mathrm{b}}\right)$ & 2.394 & 2.326 & 2.295 \\
$\theta\left(\mathrm{O}_{\mathrm{a}} \mathrm{PdO}_{\mathrm{b}}\right)$ & 40.7 & 38.537 & 41.5 \\
$\theta\left(\mathrm{P}_{\mathrm{a}} \mathrm{dPP}_{\mathrm{b}}\right)$ & 105.9 & 107.647 & 102.5
\end{tabular}

${ }^{a}$ For the experimental X-ray data see: a) Yoshida, T.; Tatsumi, K.; Matsumoto, M.; Nakatsu, K.; Nakamura, A.; Fueno, T.; Otsika, S. Nouv. J. Chim. 1979, 3, 761-774. b) Aboelella, N. W.; York, J. T.; Reynolds, A. M.; Fujita, K.; Kinsinger, C. R.; Cramer, C. J.; Riordan, C. G.; Tolman, W. B. Chem. Commun. 2004, 1716-1717. 
Table S2. Selected computed structural parameters of the optimized structures (distances $d$ in $\AA$ and angles $\theta$ in degrees) using the BS2 basis. See Figure 1 for nomenclature and labeling.

\begin{tabular}{cccccccc}
\hline $\mathbf{6}$ & $d\left(\mathrm{O}_{\mathrm{a}}-\mathrm{O}_{\mathrm{b}}\right)$ & $d\left(\mathrm{O}_{\mathrm{a}}-\mathrm{B}\right)$ & $d\left(\mathrm{Pd}-\mathrm{O}_{\mathrm{a}}\right)$ & $d\left(\mathrm{Pd}-\mathrm{O}_{\mathrm{b}}\right)$ & $\theta(\mathrm{PPdP})$ & $\theta\left(\mathrm{PdO}_{\mathrm{a}} \mathrm{B}\right)$ & $\theta\left(\mathrm{O}_{\mathrm{a}} \mathrm{O}_{\mathrm{b}} \mathrm{B}\right)$ \\
\hline $\mathbf{6 a}$ & 1.374 & 1.635 & 2.138 & 2.012 & 106.0 & 104.7 & 112.3 \\
$\mathbf{6 b}$ & 1.375 & 1.636 & 2.126 & 2.016 & 105.4 & 105.0 & 112.7 \\
$\mathbf{6 c}$ & 1.379 & 1.620 & 2.133 & 2.015 & 105.5 & 105.1 & 113.3 \\
$\mathbf{6} \mathbf{b}$ & 1.354 & 3.297 & 2.049 & 2.039 & 107.3 & 98.4 & 95.8 \\
\hline
\end{tabular}

